Online Appendix for

\title{
Bidding for Incomplete Contracts: An Empirical Analysis of Adaptation Costs
}

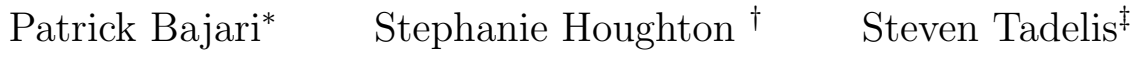

December 2012

The following Appendix provides additional details about the data and estimation procedures used in the paper. Tables A1-A3 summarize the bidding behavior of the top 20 firms in our sample, the number of participants in each auction, and the distribution of these auctions over time. The next two tables present information about our use of instruments in the reduced form regressions of bids on contract characteristics and ex post changes. Specifically, in Table A4, we present F-statistics from first-stage regressions of the instruments. Table A5 demonstrates the robustness of our results by comparing model specifications that instrument for different subsets of the potentially endogenous variables. A final section describes in detail the procedure used to obtain the structural estimates. This section also includes Table A6, which presents results for alternative specifications of the first-stage recovery of the bid distributions using fixed effects and random effects to control for unobserved auction heterogeneity.

\footnotetext{
*University of Minnesota and NBER

${ }^{\dagger}$ Texas A\&M University

${ }^{\ddagger}$ UC Berkeley
} 
Table A1: Bidding Activities of Top 20 Firms

\begin{tabular}{|c|c|c|c|c|c|c|c|c|}
\hline \multirow[t]{2}{*}{ 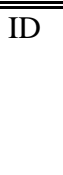 } & \multirow{2}{*}{$\begin{array}{l}\text { No. of } \\
\text { Wins }\end{array}$} & \multirow{2}{*}{$\begin{array}{c}\text { Total Bid for } \\
\text { Contracts } \\
\text { Awarded }\end{array}$} & \multirow{2}{*}{$\begin{array}{c}\text { Final Payments } \\
\text { on Contracts } \\
\text { Awarded }\end{array}$} & \multirow{2}{*}{$\begin{array}{l}\text { No. of } \\
\text { Bids } \\
\text { Entered }\end{array}$} & \multirow{2}{*}{$\begin{array}{l}\text { Participation } \\
\text { Rate }\end{array}$} & \multicolumn{3}{|c|}{ Conditional on Bidding for a Contract } \\
\hline & & & & & & Average Bid & $\begin{array}{c}\text { Average } \\
\text { Engineer's } \\
\text { Estimate }\end{array}$ & $\begin{array}{l}\text { Average } \\
\text { Distance } \\
\text { (Miles) }\end{array}$ \\
\hline 104 & 160 & $554,232,998$ & $616,115,118$ & 484 & $59.1 \%$ & $3,395,548$ & $3,379,604$ & 133.3 \\
\hline 75 & 15 & $233,245,265$ & $267,245,145$ & 42 & $5.1 \%$ & $10,607,480$ & $10,894,612$ & 81.9 \\
\hline 135 & 7 & $121,048,703$ & $102,084,697$ & 54 & $6.6 \%$ & $13,769,467$ & $13,414,968$ & 441.0 \\
\hline 244 & 23 & $87,147,853$ & $94,787,509$ & 73 & $8.9 \%$ & $3,932,621$ & $3,721,600$ & 58.3 \\
\hline 12 & 34 & $72,495,433$ & $72,215,257$ & 73 & $8.9 \%$ & $2,201,216$ & $2,377,883$ & 31.8 \\
\hline 262 & 24 & $72,088,982$ & $76,124,748$ & 101 & $12.3 \%$ & $2,806,625$ & 2,830,655 & 215.4 \\
\hline 125 & 16 & $57,970,813$ & $62,164,914$ & 74 & $9.0 \%$ & $3,236,709$ & $3,030,180$ & 81.5 \\
\hline 147 & 1 & $52,666,668$ & $53,890,666$ & 5 & $0.6 \%$ & $19,007,185$ & $19,037,046$ & 86.0 \\
\hline 251 & 23 & $48,605,745$ & $51,533,241$ & 38 & $4.6 \%$ & $1,990,136$ & $2,126,489$ & 46.3 \\
\hline 107 & 21 & $43,852,728$ & $45,655,279$ & 59 & $7.2 \%$ & $2,609,335$ & $2,688,572$ & 53.3 \\
\hline 23 & 17 & $41,695,376$ & $46,204,955$ & 67 & $8.2 \%$ & $3,123,777$ & $2,886,551$ & 67.1 \\
\hline 410 & 1 & $33,092,725$ & $36,268,057$ & 1 & $0.1 \%$ & $33,092,725$ & $28,181,000$ & 141.0 \\
\hline 237 & 22 & $31,916,930$ & $31,053,539$ & 80 & $9.8 \%$ & $2,094,049$ & $2,065,371$ & 69.7 \\
\hline 265 & 4 & $26,786,493$ & $26,426,965$ & 9 & $1.1 \%$ & $7,283,186$ & $7,406,581$ & 234.5 \\
\hline 186 & 17 & $26,566,823$ & $27,995,110$ & 53 & $6.5 \%$ & $1,621,933$ & $1,630,168$ & 48.2 \\
\hline 234 & 6 & $24,883,692$ & $27,841,209$ & 24 & $2.9 \%$ & $2,189,430$ & $2,001,743$ & 166.2 \\
\hline 162 & 17 & $23,556,856$ & $25,487,495$ & 39 & $4.8 \%$ & $1,358,393$ & $1,427,103$ & 61.9 \\
\hline 126 & 8 & $23,454,933$ & $23,719,853$ & 46 & $5.6 \%$ & $1,597,387$ & $1,633,259$ & 69.7 \\
\hline 25 & 2 & $23,118,363$ & $25,627,033$ & 13 & $1.6 \%$ & $4,954,998$ & $4,913,823$ & 44.5 \\
\hline 141 & 13 & $22,904,644$ & $24,262,589$ & 57 & $7.0 \%$ & $2,644,021$ & $2,515,985$ & 61.4 \\
\hline
\end{tabular}

Table A2: Bid Concentration Among Contracts Awarded to Lowest Bidder

\begin{tabular}{l|ccccccccccc}
\hline \hline Number of Bidders & 2 & 3 & 4 & 5 & 6 & 7 & 8 & 9 & 10 & $11+$ & Total \\
\hline Contracts in 1999 & 21 & 47 & 36 & 30 & 11 & 8 & 4 & 2 & 3 & 0 & 162 \\
Contracts in 2000 & 30 & 45 & 49 & 43 & 30 & 21 & 6 & 12 & 6 & 7 & 249 \\
Contracts in 2002 & 13 & 13 & 12 & 24 & 14 & 21 & 5 & 4 & 2 & 2 & 110 \\
Contracts in 2003 & 2 & 9 & 6 & 5 & 2 & 1 & 1 & 0 & 0 & 1 & 27 \\
Contracts in 2004 & 21 & 32 & 31 & 19 & 9 & 7 & 4 & 2 & 2 & 0 & 127 \\
Contracts in 2005 & 46 & 38 & 34 & 7 & 8 & 6 & 5 & 0 & 0 & 0 & 144 \\
\hline
\end{tabular}

Table A3: Project Distribution throughout the Year

\begin{tabular}{lcccccccccccc}
\hline \hline Month & Jan & Feb & Mar & Apr & May & Jun & Jul & Aug & Sept & Oct & Nov & Dec \\
\hline Contracts in 1999 & 13 & 11 & 19 & 12 & 18 & 18 & 24 & 20 & 13 & 4 & 8 & 2 \\
Contracts in 2000 & 12 & 14 & 23 & 36 & 16 & 26 & 10 & 39 & 24 & 21 & 20 & 8 \\
Contracts in 2002 & 4 & 8 & 11 & 19 & 24 & 11 & 7 & 2 & 14 & 3 & 7 & 0 \\
Contracts in 2003 & 0 & 0 & 0 & 0 & 0 & 0 & 2 & 8 & 5 & 4 & 2 & 6 \\
Contracts in 2004 & 2 & 8 & 15 & 29 & 33 & 6 & 6 & 10 & 7 & 7 & 3 & 1 \\
Contracts in 2005 & 4 & 10 & 24 & 26 & 23 & 17 & 5 & 6 & 10 & 10 & 5 & 4 \\
\hline
\end{tabular}


Table A4: First-Stage Results Testing Instrument Quality

\begin{tabular}{lc}
\hline \hline \multicolumn{1}{c}{ Endogenous Variable } & First Stage F-Stat \\
\hline Positive Adjustments & 23.38 \\
Negative Adjustments & 9.22 \\
Extra Work & 4.79 \\
Deductions & 5.53 \\
CCDBOverrun & 31.96 \\
& 3661 \\
Number of Observations & \\
The five categories of ex post changes are each normalized by a measure of project \\
size, $\bar{b} \cdot q^{a c t}$. These suggest that the resident engineer's identity is only strongly \\
correlated with positive adjustments and the dollar overrun on itemized tasks, but \\
weakly correlated with extra work and deductions.
\end{tabular}

Table A5: Bid Function Regressions Using Actual Quantities Instead of Estimates

\begin{tabular}{|c|c|c|c|c|c|c|c|c|c|}
\hline Variable & IV. & VII. & & $\mathrm{V}$ V. & "VIII. & & VI. & IX. & \\
\hline \multirow[t]{2}{*}{${\overline{D_{I S T}}}_{\mathrm{i}}$} & 0.0221 & 0.0217 & 0.0220 & 0.0089 & 0.0089 & 0.0089 & 0.0123 & 0.0119 & 0.0121 \\
\hline & (5.94) & (5.85) & (5.94) & (3.61) & (3.61) & (3.61) & (4.98) & (5.32) & (5.31) \\
\hline \multirow[t]{2}{*}{$\operatorname{RDIST}_{\mathrm{i}}$} & 0.0353 & 0.0347 & 0.0355 & -0.0013 & -0.0013 & -0.0013 & 0.0131 & 0.0116 & 0.0123 \\
\hline & (3.41) & (3.24) & (3.43) & $(-0.15)$ & $(-0.15)$ & $(-0.15)$ & (1.83) & (1.57) & (1.69) \\
\hline \multirow[t]{2}{*}{ FRINGE $_{\mathrm{i}}$} & -0.00004 & 0.0001 & 0.0004 & 0.034 & 0.034 & 0.034 & 0.0293 & 0.0297 & 0.0297 \\
\hline & $(-0.00)$ & $(0.02)$ & $(0.04)$ & $(6.46)$ & (6.46) & (6.46) & (5.59) & (5.32) & (5.32) \\
\hline \multirow{2}{*}{$\begin{array}{c}\text { Number of } \\
\text { Bidders }\end{array}$} & 0.0058 & 0.0062 & 0.0062 & 0.0024 & 0.0030 & 0.0028 & -0.0032 & -0.0026 & -0.0028 \\
\hline & (1.11) & $(1.21)$ & (1.19) & $(0.47)$ & $(0.58)$ & $(0.55)$ & $(-0.80)$ & $(-0.73)$ & $(-0.78)$ \\
\hline \multirow[t]{2}{*}{ NPosAdj } & 0.8032 & 0.8758 & 0.8815 & 0.8190 & 0.9044 & 0.9166 & 0.7712 & 0.9194 & 0.9319 \\
\hline & (5.89) & (3.87) & (3.92) & $(5.85)$ & (3.82) & (3.89) & (6.39) & (4.67) & (4.76) \\
\hline \multirow[t]{2}{*}{ NNegAdj } & -1.7988 & -1.6894 & -1.8365 & -1.7367 & -1.5647 & -1.7848 & -1.8894 & -1.5473 & -1.9697 \\
\hline & $(-2.23)$ & $(-1.78)$ & $(-2.25)$ & $(-2.24)$ & $(-1.72)$ & $(-2.27)$ & $(-2.25)$ & $(-1.62)$ & $(-2.87)$ \\
\hline \multirow[t]{2}{*}{ NEX } & 0.1644 & 0.2234 & 0.1644 & 0.1647 & 0.2261 & 0.1647 & 0.1559 & 0.2089 & 0.1558 \\
\hline & (1.74) & (1.64) & (1.76) & $(1.77)$ & (1.66) & (1.79) & (1.79) & (2.49) & (3.52) \\
\hline \multirow[t]{2}{*}{ NDED } & -1.0231 & -1.7460 & -0.9932 & -1.3268 & -2.4838 & -1.2893 & -0.9580 & -2.2187 & -0.9337 \\
\hline & $(-1.31)$ & $(-0.99)$ & $(-1.28)$ & $(-1.84)$ & $(-1.30)$ & $(-1.80)$ & $(-1.46)$ & $(-1.58)$ & $(-1.22)$ \\
\hline \multirow[t]{2}{*}{ NOverrun } & 0.0057 & 0.0065 & 0.0066 & 0.0059 & 0.0068 & 0.0069 & 0.0054 & 0.0070 & 0.0071 \\
\hline & (5.46) & (3.72) & (3.79) & $(5.46)$ & (3.70) & (3.78) & $(5.76)$ & (3.94) & $(4.04)$ \\
\hline \multirow[t]{2}{*}{ Constant } & 0.9054 & 0.8967 & 0.9015 & -0.0518 & -0.0628 & -0.0564 & 0.9556 & 0.9443 & 0.9480 \\
\hline & (31.74) & (29.73) & (31.30) & $(-1.91)$ & $(-2.17)$ & $(-2.06)$ & $(44.80)$ & (44.59) & $(46.82)$ \\
\hline Project Effects & None & None & None & Fixed & Fixed & Fixed & Random & Random & Random \\
\hline \multirow[t]{2}{*}{ Instruments } & None & Resident & Resident & None & Resident & Resident & None & Resident & Resident \\
\hline & & Engineer & $\begin{array}{l}\text { Engineer, } \\
\text { only for } \\
\text { NPosAdj, } \\
\text { NOverrun }\end{array}$ & & Engineer & $\begin{array}{l}\text { Engineer, } \\
\text { only for } \\
\text { NPosAdj, } \\
\text { NOverrun }\end{array}$ & & Engineer & $\begin{array}{c}\text { Engineer, } \\
\text { only for } \\
\text { NPosAdj, } \\
\text { NOverrun }\end{array}$ \\
\hline $\mathrm{R}^{2}$ & 0.0738 & 0.0712 & 0.0732 & 0.7621 & 0.7621 & & 0.0599 & 0.0577 & 0.0581 \\
\hline Num. of Obs. & 3661 & 3661 & 3661 & 3661 & 3661 & 3661 & 3661 & 3661 & 3661 \\
\hline
\end{tabular}

This table reproduces six of the columns from Table 7 in the body of the paper. An additional column has been added for each of the no/fixed/random effects specifications, showing the estimates when we only instrument for NPosAdj and NOverrun where instrument strength is not an issue. Note the similarity in our estimates across specifications. As with Table 7, the dependent variable for all nine regressions is the vector product of the unit price bids and the actual quantities, divided by a measure of the project size $\left(q^{a c t} \cdot \bar{b}\right)$. Cluster-robust standard errors are used to compute t-Statistics, shown in parentheses. NOverrun is a measure of the quantity-related overrun on standard contract items, calculated as the vector product of the CCDB prices (where available) and the difference between actual and estimated quantities. 


\section{A Details on the Structural Estimation}

Our structural approach uses a two-step semiparametric estimator that builds on those discussed in Elyakime, Laffont, Loisel, and Vuong (1994) and Guerre, Perrigne, and Vuong (2000). ${ }^{1}$ In the first step, we estimate the density and the CDF of the bid distribution for project $n$, denoted by $h_{j}^{(n)}$ and $H_{j}^{(n)}$ respectively. In the second step, we use those estimates in a GMM estimator based on the first-order conditions in Equation (4). This allows us to recover the adjustment cost coefficients, $\tau_{a+}, \tau_{a-}, \tau_{d}$, and $\tau_{x}$, along with a specific form of the penalty from skewed bidding captured by the parameter $\sigma$.

\section{Step 1: Estimating Bid Distributions}

Because the bidder's payoff function contains expectations of the probability that his bid is the lowest, the first-order conditions will contain the density and CDF of the bid distributions. Specifically, we are interested in an estimate for

$$
\left(\sum_{j \neq i} \frac{h_{j}^{(n)}\left(\mathbf{b}_{i}^{(n)} \cdot \mathbf{q}^{e,(n)}\right)}{1-H_{j}^{(n)}\left(\mathbf{b}_{i}^{(n)} \cdot \mathbf{q}^{e,(n)}\right)}\right)^{-1}
$$

for each contract $n$ and each bidder $i$. As we note in the paper, we cannot recover fully nonparametric estimates of these distributions while still controlling for important measures of firm-specific and auction-specific heterogeneity. Instead we use the following semiparametric approach that "homogenizes" the submitted bids from all firms and all contracts, and uses the homogenized bids to consistently estimate the underlying distribution of firm valuations.

First, we regress the normalized bid on the firm's distance and a fringe indicator, allowing for project-specific random effects:

$$
\frac{\mathbf{b}_{j}^{(n)} \cdot \mathbf{q}^{e,(n)}}{\overline{\mathbf{b}}^{(n)} \cdot \mathbf{q}^{e}}=x_{j}^{(n)} / \mu+u^{(n)}+\varepsilon_{j}^{(n)}
$$

where $x_{j}^{(n)}$ includes the bidder's distance to the job site and an indicator for whether the bidder is a fringe firm (with less than $1 \%$ of the value of contracts awarded). Let $\hat{\varepsilon}_{j}^{(n)}$ denote the fitted residual from this regression:

$$
\hat{\varepsilon}_{j}^{(n)}=\frac{\mathbf{b}_{j}^{(n)} \cdot \mathbf{q}^{e,(n)}}{\overline{\mathbf{b}}^{(n)} \cdot \mathbf{q}^{e}}-x_{j}^{(n) \prime} \hat{\mu}-\hat{u}^{(n)}
$$

\footnotetext{
${ }^{1}$ This approach is detailed in the Athey and Haile (2007) chapter of the Handbook of Econometrics, and similar versions are applied in Krasnokutskaya (2011) and Shneyerov (2006).
} 
These residuals are assumed to be iid with distribution $G_{\mathcal{N}}(\cdot)$, where $\mathcal{N}$ indexes the distribution by the number of bidders in contract $(n)$. We can use the empirical distribution of these residuals to recover an estimate for the distribution of bids, since as we show in the paper,

$$
H_{j}^{(n)}(b) \equiv G_{\mathcal{N}}\left(\frac{b}{\overline{\mathbf{b}}^{(n)} \cdot \mathbf{q}^{e,(n)}}-x_{j}^{(n) \prime} \mu-u^{(n)}\right)
$$

Specifically, in order to construct $\hat{H}_{j}^{(n)}\left(\mathbf{b}_{i}^{(n)} \cdot \mathbf{q}^{e,(n)}\right)$, we first compute the empirical CDF of the residuals, $\hat{G_{\mathcal{N}}}(\cdot)$, by pooling all residuals from bids on contracts with the same number of bidders, $\mathcal{N}$, as in contract $(n) .^{2}$ Then we evaluate this distribution at $\frac{\mathbf{b}_{i}^{(n)} \cdot \mathbf{q}^{e,(n)}}{\overline{\mathbf{b}}^{(n)} \cdot \mathbf{q}^{e,(n)}}-x_{j}^{(n) \prime} \hat{\mu}-\hat{u}^{(n)}$ to determine the probability that bidder $i$ 's bid of $\mathbf{b}_{i}^{(n)} \cdot \mathbf{q}^{e,(n)}$, normalized, would be less than his rival bidder $j$ 's, normalized bid. Put simply, we count the fraction of the fitted residuals that are less than $\frac{\mathbf{b}_{i}^{(n)} \cdot \mathbf{q}^{e,(n)}}{\overline{\mathbf{b}}^{(n)} \cdot \mathbf{q}^{e,(n)}}-x_{j}^{(n) \prime} \hat{\mu}-\hat{u}^{(n)}$. This is done for each contract $n$ and each bidder $i$, for each of bidder $i$ 's rivals, indexed by $j$.

Next, in order to recover the empirical density of the bids, $\hat{H}_{j}^{(n)}\left(\mathbf{b}_{i}^{(n)} \cdot \mathbf{q}^{e,(n)}\right)$, we need an estimate of the empirical density of the residuals, $g_{\mathcal{N}}(\cdot)$, where again, $\mathcal{N}$ indexes the density by the number of bidders in contract $(n)$. We use a kernel density estimator, with a normal kernel and a bandwidth determined by Silverman's rule of thumb (a value of 0.0255 for our data). ${ }^{3}$ Using a change of variables, we convert this estimated residual density to an estimate of the bid density:

$$
\hat{h}_{j}^{(n)}(b)=\frac{1}{\overline{\mathbf{b}}^{(n)} \cdot \mathbf{q}^{e,(n)}} \cdot \hat{g}_{\mathcal{N}}\left(\frac{b}{\overline{\mathbf{b}}^{(n)} \cdot \mathbf{q}^{e,(n)}}-x_{j}^{(n) \prime} \hat{\mu}-\hat{u}^{(n)}\right)
$$

We use the above to calculate $\hat{h}_{j}^{(n)}\left(\mathbf{b}_{i}^{(n)} \cdot \mathbf{q}^{e,(n)}\right)$ for each contract $n$ (with number of bidders, $\mathcal{N}$ ) and each bidder $i$, for each of bidder $i$ 's rivals, indexed by $j$. Each of the resulting values are then combined with the estimates of the CDF to form the expression in 1.

Note that the estimates of both $\hat{H}_{j}^{(n)}(b)$ and $\hat{h}_{j}^{(n)}(b)$ make use of bidder- and projectspecific information, as they are evaluated at values that depend on the project's size, $\overline{\mathbf{b}}^{(n)} \cdot \mathbf{q}^{e,(n)}$, rival bidder $j$ 's characteristics $x_{j}^{(n)}$, and the unobserved project heterogeneity, $\hat{u}^{(n)}$. Furthermore, a separate distribution is estimated for each set of $\mathcal{N}$ bidders to account for the fact that, in equilibrium, the distribution of bids will be different in a 2-firm auction

\footnotetext{
${ }^{2}$ We thank an anonymous referee for reminding us to emphasize that in a first-price auction, the distribution of the mean zero $\varepsilon_{j}^{(n)}$ will vary by the number of bidders in equilibrium. That is, there is a separate empirical distribution for contracts where $\mathrm{n}=2$ (which we estimate using residuals from 266 bids), $\mathrm{n}=3$ (estimated using residuals from 552 bids), $\mathrm{n}=4$ ( 671 bids), $\mathrm{n}=5$ (639 bids), $\mathrm{n}=6$ (444 bids), $\mathrm{n}=7$ (448 bids), $\mathrm{n}=8$ (200 bids), $\mathrm{n}=9$ (180 bids), $\mathrm{n}>=10$ (261 bids). We pool contracts with over 10 bidders as there are a limited number of contracts with such large sets of bidders.

${ }^{3}$ Varying this bandwidth slightly did not significantly alter the results.
} 
as compared to a 5-firm auction, since bidders know the number of participants at the time of bidding. These estimated distributions are reasonably precise, drawing upon anywhere from 180 to 671 observed bids. The Matlab code to construct these estimates is available as a supplement to this online appendix.

\section{Step 2: GMM Estimation of the First-Order Conditions}

We use the estimates from Step 1 to construct $\left(\sum_{j \neq i} \frac{\hat{h}_{j}^{(n)}\left(\mathbf{b}_{i}^{(n)} \cdot \mathbf{q}^{e,(n)}\right)}{1-\hat{H}_{j}^{(n)}\left(\mathbf{b}_{i}^{(n)} \cdot \mathbf{q}^{e,(n)}\right)}\right)^{-1}$. This term is found in the bidder's first-order condition given in equation (10) of the paper. Following that equation, we can construct the composite error, $\widetilde{e}_{i}^{(n)}$, as:

$$
\begin{aligned}
\widetilde{e}_{i}^{(n)}=\quad & \frac{1}{\overline{\mathbf{b}}^{(n)} \cdot \mathbf{q}^{a,(n)}}\left(\mathbf{b}_{i}^{(n)} \cdot \mathbf{q}^{a,(n)}-\sum_{t=1}^{T} \frac{d b_{t}^{i}\left(s^{i}\right)}{d s^{i}} q_{t}^{a,(n)}\left(\sum_{j \neq i} \frac{\hat{h}_{j}^{(n)}\left(\mathbf{b}_{i}^{(n)} \cdot \mathbf{q}^{e,(n)}\right)}{1-\hat{H}_{j}^{(n)}\left(\mathbf{b}_{i}^{(n)} \cdot \mathbf{q}^{e,(n)}\right)}\right)^{-1}\right) \\
& +\frac{1}{\overline{\mathbf{b}}^{(n)} \cdot \mathbf{q}^{a,(n)}}\left[\left(1-\tau_{a+}\right) A_{+}^{(n)}+\left(1+\tau_{a-}\right) A_{-}^{(n)}+\left(1-\tau_{x}\right) X^{(n)}+\left(1+\tau_{d}\right) D^{(n)}\right] \\
& -\frac{1}{\overline{\mathbf{b}}^{(n)} \cdot \mathbf{q}^{a,(n)}}\left[P\left(\mathbf{b}^{i(n)}\right)-\sum_{t=1}^{T} \frac{d b_{t}^{i}\left(s^{i}\right)}{d s^{i}} \frac{\partial P\left(\mathbf{b}^{i(n)}\right)}{\partial b_{t}^{i}}\left(\sum_{j \neq i} \frac{\hat{h}_{j}^{(n)}\left(\mathbf{b}_{i}^{(n)} \cdot \mathbf{q}^{e,(n)}\right)}{1-\hat{H}_{j}^{(n)}\left(\mathbf{b}_{i}^{(n)} \cdot \mathbf{q}^{e,(n)}\right)}\right)^{-1}\right]
\end{aligned}
$$

where we parameterize $P\left(\mathbf{b}^{i(n)}\right)$ as

$$
P\left(\mathbf{b}^{i(n)}\right)=\sigma \sum_{t=1}^{T}\left(b_{t}^{i}-\bar{b}_{t}\right)^{2}\left|\frac{q_{t}^{e}-q_{t}^{a}}{q_{t}^{e}}\right|
$$

We form the moment condition

$$
m_{N}\left(\sigma, \tau_{a+}, \tau_{a-}, \tau_{d}, \tau_{x}, \hat{h}, \hat{H}\right)=\frac{1}{N} \sum_{n} \sum_{i} \widetilde{e}_{i}^{(n)}\left(\sigma, \tau_{a+}, \tau_{a-}, \tau_{d}, \tau_{x}, \hat{h}, \hat{H}\right)\left(z_{i}^{(n)}-\bar{z}_{i}^{(n)}\right)
$$

where the instruments, $z_{i}^{(n)}$ include the engineer's estimate, a full set of dummy variables for the resident engineer assigned to the project, and (in some specifications) month and district dummy variables. We use a non-linear least squares optimization algorithm (Matlab's Isqnonlin) to minimize the objective function $m_{N}^{\prime} W m_{N}$, where $W$ is a positive semi-definite weighting matrix. We first estimate $\left(\widehat{\sigma}, \widehat{\tau_{a+}}, \widehat{\tau_{a-}}, \widehat{\tau_{d}}, \widehat{\tau_{x}}\right)$ using the identity weighting matrix, then use those estimates to construct the optimal weighting matrix as the inverse of the sample variance of $m_{N}$. 
Table A6: Structural Estimation, using Alternative Specifications for the First-Stage Recovery of the Bid Distributions

\begin{tabular}{|c|c|c|c|c|c|c|c|c|}
\hline & I-A & I-B & III-A & II-B & III-A & III-B & IV-A & IV-B \\
\hline \multicolumn{9}{|l|}{ Implied Marginal Transaction Costs } \\
\hline Positive Adjustments $\left(\tau^{A+}\right)$ & $\begin{array}{c}4.759 \\
(4.032)\end{array}$ & $\begin{array}{c}2.203 \\
(0.409)\end{array}$ & $\begin{array}{c}4.192 \\
(2.121)\end{array}$ & $\begin{array}{c}2.224 \\
(0.373)\end{array}$ & $\begin{array}{c}4.523 \\
(4.015)\end{array}$ & $\begin{array}{c}2.132 \\
(0.401)\end{array}$ & $\begin{array}{c}4.557 \\
(2.113)\end{array}$ & $\begin{array}{c}2.236 \\
(0.379)\end{array}$ \\
\hline Negative Adjustments $\left(\tau^{A+}\right)$ & $\begin{array}{c}-0.994 \\
(53.680)\end{array}$ & $\begin{array}{c}0.305 \\
(3.156)\end{array}$ & $\begin{array}{l}-15.145 \\
(33.565)\end{array}$ & $\begin{array}{c}4.802 \\
(4.323)\end{array}$ & $\begin{array}{c}-0.268 \\
(53.686)\end{array}$ & $\begin{array}{l}0.743 \\
(3.08)\end{array}$ & $\begin{array}{c}-1.863 \\
(33.572)\end{array}$ & $\begin{array}{c}2.758 \\
(3.015)\end{array}$ \\
\hline Extra Work $\left(\tau^{X}\right) *$ & $\begin{array}{c}1.091 \\
(2.708)\end{array}$ & $\begin{array}{c}1.084 \\
(0.152)\end{array}$ & $\begin{array}{c}2.449 \\
(1.470)\end{array}$ & $\begin{array}{c}1.233 \\
(0.203)\end{array}$ & $\begin{array}{c}1.079 \\
(2.708)\end{array}$ & $\begin{array}{c}1.076 \\
(0.154)\end{array}$ & $\begin{array}{c}2.209 \\
(1.469)\end{array}$ & $\begin{array}{c}1.227 \\
(0.198)\end{array}$ \\
\hline Deductions $\left(\tau^{D}\right)$ & $\begin{array}{c}9.069 \\
(77.845)\end{array}$ & $\begin{array}{c}0.556 \\
(4.878)\end{array}$ & $\begin{array}{c}10.574 \\
(39.989)\end{array}$ & $\begin{array}{c}2.881 \\
(3.860)\end{array}$ & $\begin{array}{c}7.200 \\
(77.904)\end{array}$ & $\begin{array}{c}0.033 \\
(4.844)\end{array}$ & $\begin{array}{c}4.246 \\
(40.035)\end{array}$ & $\begin{array}{c}1.478 \\
(3.601)\end{array}$ \\
\hline \multicolumn{9}{|l|}{ Skewing Parameter } \\
\hline Penalty $(\sigma)$ & $\begin{array}{c}-4.699 \mathrm{E}-05 \\
(5.69 \mathrm{E}-05)\end{array}$ & $\begin{array}{l}-1.225 \mathrm{E}-05 \\
(1.00 \mathrm{E}-05)\end{array}$ & $\begin{array}{l}-4.235 E-05 \\
(3.38 E-05)\end{array}$ & $\begin{array}{l}-1.309 \mathrm{E}-05 \\
(9.10 \mathrm{E}-06)\end{array}$ & $\begin{array}{l}-4.35 \mathrm{E}-05 \\
(5.56 \mathrm{E}-05)\end{array}$ & $\begin{array}{l}-1.11 \mathrm{E}-05 \\
(9.49 \mathrm{E}-06)\end{array}$ & $\begin{array}{l}-4.84 \mathrm{E}-05 \\
(3.31 \mathrm{E}-05)\end{array}$ & $\begin{array}{l}-1.22 \mathrm{E}-05 \\
(1.04 \mathrm{E}-05)\end{array}$ \\
\hline $\begin{array}{l}\text { Number of Obs } \\
\text { First-Stage Bid Distribution** }\end{array}$ & $\begin{array}{c}3661 \\
\text { Contract } \\
\text { Fixed } \\
\text { Effects }\end{array}$ & $\begin{array}{c}3661 \\
\text { Contract } \\
\text { Fixed } \\
\text { Effects }\end{array}$ & $\begin{array}{c}3661 \\
\text { Contract } \\
\text { Fixed } \\
\text { Effects }\end{array}$ & $\begin{array}{c}3661 \\
\text { Contract } \\
\text { Fixed } \\
\text { Effects }\end{array}$ & $\begin{array}{c}3661 \\
\text { Contract } \\
\text { Random } \\
\text { Effects }\end{array}$ & $\begin{array}{c}3661 \\
\text { Contract } \\
\text { Random } \\
\text { Effects }\end{array}$ & $\begin{array}{c}3661 \\
\text { Contract } \\
\text { Random } \\
\text { Effects }\end{array}$ & $\begin{array}{c}3661 \\
\text { Contract } \\
\text { Random } \\
\text { Effects }\end{array}$ \\
\hline $\begin{array}{l}\text { Weighting Matrix*** } \\
\text { Instruments Used in Second Stage } \\
\text { GMM }\end{array}$ & Identity & $\begin{array}{l}\text { Optimal } \\
\text { Resident } \\
\text { Engineer, } \\
\text { Engineer's } \\
\text { Estimate }\end{array}$ & Identity & $\begin{array}{l}\text { Optimal } \\
\text { Resident } \\
\text { Engineer, } \\
\text { Engineer's } \\
\text { Estimate, } \\
\text { Month and } \\
\text { District } \\
\text { Dummies }\end{array}$ & Identity & $\begin{array}{l}\text { Optimal } \\
\text { Resident } \\
\text { Engineer, } \\
\text { Engineer's } \\
\text { Estimate }\end{array}$ & Identity & $\begin{array}{c}\text { Optimal } \\
\text { Resident } \\
\text { Engineer, } \\
\text { Engineer's } \\
\text { Estimate, } \\
\text { Month and } \\
\text { District } \\
\text { Dummies }\end{array}$ \\
\hline
\end{tabular}

* These estimates represent an upper bound on transaction costs associated with changes in scope. They do not account for marginal costs associated with performing the extra work, which for a reasonable profit margin of 20 percent would lower our estimate by $\$ 0.80$.

** To recover the bid distribution from which the moment conditions (based on the first-order conditions) are formed, we obtain residuals from a first stage regression of bids on contract and bidder characteristics. This "homogenizes” the data by controlling for contract- and bidder-specific characteristics. In Columns I-A, I-B, II-A, and II-B, the first-stage regression includes bidder distance, fringe status, and a contract fixed effect. In Columns III-A, III-B, IV-A, and IV-B, the first-stage regression includes bidder distance, fringe status, the number of bidders, and a contract random effect (the fixed effect approach did not include the number of bidders as it would have been fully absorbed by the fixed effect. In both cases, the residuals for all 3661 bids (819 contracts) were then pooled in order to recover the bidding distribution from which bidders would form their expectations of winning. This differs from the approach in the paper - where separate distributions are recovered for each set of contracts with the same number of bidders - but the resulting estimates are very similar. We prefer the indexing approach used in the paper, as it trades off a higher variance (fewer observations used to construct each distribution) in favor of unbiasedness.

*** Consistent GMM estimates were computed using the identity matrix as the weighting matrix. In a second step, efficient GMM estimates were computed using the optimal weighting matrix derived from the variance of the sample moments in the first step. Standard errors appear in parentheses. 